\title{
Burnout and Conservation Practices of Nurses of Tertiary Hospital in Negros Occidental
}

\author{
Jecho G. Balgos ${ }^{1}$ and Sheila P. Arnibal ${ }^{2}$ \\ ${ }^{1}$ Corazon Locsin Montelibano Memorial Regional Hospital, Bacolod City, Philippines \\ 2University of Negros Occidental-Recoletos, Bacolod City, Philippines
}

\begin{tabular}{l} 
Article history \\
Submitted: 23 October 2020 \\
Revised: 1 November 2020 \\
Accepted: 13 November 2020 \\
\hline Keywords \\
Nursing \\
Burnout \\
Conservation Practices \\
Nurses \\
Tertiary Hospital \\
Descriptive-Correlational \\
Negros Occidental
\end{tabular}

Introduction. Burnout occurs in any given occupation. In the previous research about burnout, it shows that its prevalence is high among practitioners in the field of healthcare. With several factors to burnout, it eventually leads to compromised patient care and the occurrence of patient safety issues. Studies showed that less conservation could lead to the progression of burnout. Levine's theory of conservation includes the concept of conservation of energy, combined with the psychosocial aspects of the individual's needs that when all operate together, it will promote healing. Thus, this paper aims to assess the level of burnout and the extent of Conservation practices of Nurses of Tertiary Hospital in Negros Occidental. Furthermore, it explored significant relationships between variables sex, age, years of service, employment status, educational attainment, and areas of assignment and levels of burnout. Also, it intends to correlate the aforementioned variables and conservation practice, and burnout and conservation practices. Finally, it explores the predictors of the conservation practices of nurses.

Methods. The descriptive-correlational design was utilized to assess the levels of burnout and extent of conservation practices of nurses in a Tertiary Hospital in Negros Occidental. The respondents were the 202 nurses in a Tertiary Hospital in Negros Occidental that provides direct patient care in both wards and special areas. To get nurses' representativeness in the area of assignments, the researcher utilized the stratified random sampling by settings. The fishbowl method was used for the randomization of the respondents. For the research instrument, a standardized Oldenburg Burnout Inventory questionnaire was used to measure the levels of burnout. A researcher-made questionnaire was formulated inspired by Levine's Conservation theory to determine the extent of conservation practices of nurses, and a researcher-made checklist was used to identify the risk factors contributing to the burnout of nurses. For data analysis, utilization of Mean, Standard Deviation, and Spearman rank to define significant relationships between variables, while Linear Regression was applied to determine predictors of the conservation practices of nurses. Moreover, the researcher employed the use of frequency to identify the risk factors of nurse burn out.

Results. The findings of the study showed that the levels of burnout of nurses in the tertiary hospital are interpreted as somehow stressful. The nurses in the tertiary hospital experience burnout regardless of their demographic profile. In relation to the aforementioned variables and levels of burnout, the aforementioned variable, and the extent of nurses' conservation practices, it reveals that there is no significant relationship between the aforementioned variables and burnout and the aforementioned variables and extent of conservation. As to the extent of conservation practices, the result showed that they have a high extent of conservation practices with a moderate extent of conservation in the area of energy integrity regardless of variables. However, there is a significant relationship between burnout and the conservation practices of nurses. Moreover, educational attainment as a variable can predict the extent of conservation practices of nurses in a tertiary hospital.

Conclusion. Most nurses in the tertiary hospital experience a level of burnout. However, nurses can cope and adapt by executing certain practices specific to the four aspects of the conservation: energy, personal integrity, physical integrity, and social integrity. Since nurses have a moderate extent in energy conservation, there is a need to reinforce or modify practices to effectively improve energy 
conservation to avoid exhaustion and prevent burnout. The aforementioned variables do not influence their levels of burnout and extent of conservation practices except for educational attainment, where nurses with a master's degree can influence the extent of conservation practices positively. The healthcare institution's administrator and related offices have important roles in formulating, organizing, and implementing essential programs, not only limited to fostering mental health and awareness. Nevertheless, a holistic approach that will prevent the complications of burnout, such as mental illness, dysfunctional performance, and job dissatisfaction, has a greater impact on restoring nurses' overall welfare in a tertiary hospital. Furthermore, among the first five factors contributing to nurses' burnout are nurse shortage, unequal nurse-patient ratio, duty schedule (shifting), regular overtime (>8hours/day) and complex nursing roles.

Practical Value of the Paper. The research paper contributes to the related studies concerning nurse's burnout in the Philippines and global settings since burnout is a widespread phenomenon. Moreover, the findings of the study may serve as baseline data for the administrators in making essential and comprehensive programs, especially in preventing the prevalence of burnout among nurses. Also, to future researchers, this will serve as evidence-based data to further explore the limitation of this study and discover relevant issues concerning burn out.

\section{References}

Abedi-Gilavandi, R., Fateme, T., Abedi-Taleb, E., Nateghi, S., Khedmat, L., Amini, F., Moshfeghi, S., \& Effatpanah, M. (2019). Burnout Among Nursing Staff in Ziaeian Hospital. Retrieved from https://www.ncbi.nlm.nih.gov/pmc/ articles/PMC6511368/

Amiri, M., Khosravi, A., Eghtesadi, A. R., Sadeghi, Z., Abedi, G., \& Ranjbar, M. (2016). Burnout and its Influencing Factors among Primary Health Care Providers in the NorthEast of Iran. Retrieved from https://journals.plos. org/plosone/article?id=10.1371/journal.pone.0167648

Bakker, A., \& Demerouti, E. (2008). The Oldenburg Burnout Inventory: A Good Alternative to Measure Burnout and Engagement. Retrieved from https://www.academia.edu/2796247/The_Oldenburg_

Burnout_Inventory_A_good_alternative_to_measure_burnout_and_engagement Hall, L., Johnson, J., Watt, I., Tsipa, A., \& O'Connor, D. (2016). Healthcare Staff Wellbeing, Burnout, and Patient Safety: A Systematic Review. Retrieved from https://www.ncbi.nlm.nih.gov/pmc/articles/PMC4938539/

Maslach, C \& Schaufeli, W. (2017). Historical and Conceptual Development of Burnout. Retrieved from https://www. taylorfrancis.com/books/e/9781315227979/chapters/10.4324/9781315227979-1

Mbanga, C., Makebe, H., Tim, D., Fonkou, S., Toukam, L., \& Njim, T. (2018). Determinants of burnout syndrome among nurses in Cameron. Retrieved from https://www.ncbi.nlm.nih.gov/pmc/articles/PMC6038299/

Mudallal, R. H., Othman, W. M., \& Al Hassan, N. L. (2017). Nurses' Burnout: The Influence of Leader Empowering Behaviors, Work Conditions, and Demographic Traits Retrieved from https://journals.sagepub.com/doi/ full/10.1177/0046958017724944

Pinto, M. et al. (2015). Coping strategies of nurses in hospital emergency care services. Retrieved from https://www. scielo.br/scielo.php?pid=S0103-21002015000300216\&script=sci_arttext\&tIng =en

Prapanjaroensin, A et al., (2017). Conservation of Resources Theory in Nurse Burnout and Patient Safety. Retrieved from https://www.ncbi.nlm.nih.gov/pubmed/28543427

World Health Organization [WHO]. (2019). Burnout an "occupational phenomenon": International Classification of Diseases. Retrieved from https://www.who.int/mental_health/evidence/burn-out/en/

\section{Correspondence:}

Jecho G. Balgos [jecho_nexus@yahoo.com]

http://orcid.org/0000-0003-2670-2716 